\title{
KNOWLEDGE AND PRACTICES ABOUT MENSTRUAL HYGIENE AMONG SCHOOL ADOLESCENT GIRLS IN AGROHA VILLAGE OF HARYANA
}

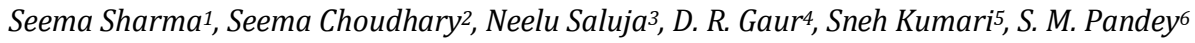 \\ ${ }^{1}$ Associate Professor, Department of Community Medicine, Maharaja Agrasen Institute of Medical Education and Research, Agroha, \\ Hisar, Haryana. \\ 2Professor, Department of Community Medicine, MAMC, Maharaja Agrasen Institute of Medical Education and Research, Agroha, Hisar, \\ Haryana. \\ ${ }_{3}^{3}$ Associate Professor, Department of Community Medicine, MAMC, Maharaja Agrasen Institute of Medical Education and Research, \\ Agroha, Hisar, Haryana. \\ ${ }^{4}$ Professor and HOD, Department of Community Medicine, MAMC, Maharaja Agrasen Institute of Medical Education and Research, \\ Agroha, Hisar, Haryana. \\ ${ }^{5}$ Assistant Professor, Department of Community Medicine, MAMC, Maharaja Agrasen Institute of Medical Education and Research, \\ Agroha, Hisar, Haryana. \\ ${ }^{6}$ Assistant Professor (Stats), Department of Community Medicine, MAMC, Maharaja Agrasen Institute of Medical Education and \\ Research, Agroha, Hisar, Haryana.
}

\section{ABSTRACT}

Menstruation is a phenomenon unique to the females. Adolescent girls often lack knowledge regarding reproductive health including menstrual hygiene which can be due to socio-cultural barriers in which they grow up. Learning about menstrual hygiene is a vital aspect of health education for adolescent girls.

\section{OBJECTIVES}

a) To assess the knowledge and practices of menstrual hygiene among rural school going adolescent girls; b) To assess the restrictions practiced by school adolescent girls during menstruation.

\section{METHODS AND MATERIALS}

A cross-sectional study was carried out in Govt. Senior Secondary Girls School located near the Primary Health Centre, Agroha, Hisar. Total 150 adolescent girls (Aged 11-16 yrs.), who had attained menarche were only included in the study. A pre-designed pretested semi-structured questionnaire was prepared for collection of data.

\section{STATISTICAL ANALYSIS}

Mean and Proportions.

\section{RESULTS}

In this study, 95.3\% adolescent girls were aware of menstruation before menarche. In most of the cases mother was the most common source of information. Only $38.7 \%$ girls knew that bleeding occurs from uterus. A total of $71.3 \%$ girls were aware that the menstruation is a physiological process. Out of total, $80.7 \%$ girls used sanitary napkins during menstruation. In this study, $92 \%$ girls faced restrictions regarding religious matters. Eighty four percent adolescent girls took bath daily during menstruation and $90 \%$ washed their hands every time after visit to the toilet. Only $75.3 \%$ girls washed their external genitalia regularly.

\section{CONCLUSIONS}

In this study knowledge was better than the practice; therefore, the adolescent girls should be educated about the process and significance of menstruation as well as use of proper pads or absorbents and its proper disposal.

\section{KEYWORDS}

School Adolescent Girls, Menstruation, Menstrual Hygiene, Village.

HOW TO CITE THIS ARTICLE: Sharma S, Choudhary S, Saluja N, et al. Knowledge and practices about menstrual hygiene among school adolescent girls in Agroha village of Haryana. J. Evolution Med. Dent. Sci. 2016;5(9):389-392,

DOI: $10.14260 /$ jemds/2016/89

\section{INTRODUCTION}

Menstruation is a phenomenon unique to the females. Adolescence in girls has been recognized as a special period, which signifies the transition from girlhood to womanhood.

Financial or Other, Competing Interest: None.

Submission 18-12-2015, Peer Review 12-01-2016,

Acceptance 19-01-2016, Published 01-02-2016.

Corresponding Author:

Dr. Seema Sharma,

Associate Professor, Department of Community Medicine,

Maharaja Agrasen Medical College, Agroha,

Hisar, Haryana-125047.

E-mail: ss4_gunu@yahoo.co.in

DOI: $10.14260 /$ jemds/2016/89
Learning about menstrual hygiene is a vital aspect of health education for adolescent girls. Menstruation is generally considered as unclean in the Indian society. Isolation of the menstruating girls and restrictions being imposed on them in the family, have reinforced a negative attitude towards this phenomenon. ${ }^{1}$ Social prohibitions and the negative attitude of parents in discussing the related issues openly have blocked the access of adolescent girls to the right kind of information, especially in the rural and tribal communities. ${ }^{2}$

Menstruation and menstrual practices are still clouded by taboos and socio-cultural restrictions resulting in adolescent girls remaining ignorant of the scientific facts and hygienic health practices, which sometimes result into adverse health outcomes. The present study was designed to assess the 
knowledge, beliefs and source of information regarding menstruation among the adolescent school girls of the secondary school and also to identify the status of menstrual hygiene among them. ${ }^{3}$

Menstrual hygiene is an issue that is insufficiently acknowledged and has not received adequate attention in the reproductive health as well as Water, Sanitation and Hygiene (WASH) sectors in developing countries including India. Also, its relationship with and impact on achieving many Millennium Development Goals (MDGs). Studies that make the issues visible to the concerned policymakers and informed practical actions are very much warranted. ${ }^{4}$ Menstruation is still regarded as something unclean or dirty in Indian society. The reaction to menstruation depends upon awareness and knowledge about the subject.

The manner in which a girl learns about menstruation and its associated changes may have an impact on her response to the event of menarche.$^{5}$ although menstruation is a natural process; it is linked with several misconceptions and practices, which sometimes result into adverse health outcomes. Hygiene related practices of women during menstruation are of considerable importance, especially in terms of increased vulnerability to Reproductive Tract Infections (RTI). ${ }^{6}$

Therefore, increased knowledge about menstruation right from childhood may escalate safe practices and may help in mitigating the suffering of millions of women. With this background the present study was undertaken to assess the knowledge, beliefs and source of information regarding menstruation among the adolescent school girls of the Secondary school and also to identify the status of menstrual hygiene among them.

\section{OBJECTIVES}

1. To assess the knowledge and practices of menstrual hygiene among school going adolescent girls in Agroha village.

2. To assess the restrictions practised by school adolescent girls during menstruation.

\section{MATERIALS AND METHODS}

One hundred and fifty adolescent girls between 11-16 years of age from a Govt. Girls Senior Secondary School of Agroha village were involved in this study. It was a cross-sectional school based study among adolescent girls. There was only a single girl's school near Primary Health Centre Agroha, which is a teaching and training rural health centre attached to Maharaja Agrasen Medical College Agroha. Hence, this school was purposively selected for the study. Total 150 adolescent girls (Aged 11-16 yrs.); who had attained menarche were included in this study. Adolescents who were present in the schools during the days of survey constituted the sample size. A pre-designed and pre-tested semi-structured questionnaire was prepared for collection of data.

The school authority was contacted and the purpose of the study was explained. After obtaining the permission from the school authorities, the school was visited as per preplanned schedule for getting information from the adolescent girls. A list of adolescent girls who had attained menarche was prepared beforehand with the help of the school teachers. The adolescent girls were explained about the purpose of the study and were assured of confidentiality.

A verbal consent was obtained from the girls before administering the questionnaire. They were instructed on how to fill the questionnaire. Adequate time was given to fill up the questionnaire. After completing the questionnaire, the students were asked to place their sheets in a box provided at the corner of the hall. After collection the whole data was compiled and analysed. Statistical analysis was done on the basis of mean and proportions.

\section{RESULTS}

Table 1 shows majority (42.7\%) of adolescent girls were in 1416 yrs. of age group Table 2 shows the distribution of adolescent girls as per their menarche. The mean age of menarche of the respondents was 12.7 years. Table 3 shows a total of $95.3 \%$ adolescent girls were aware of menstruation before their menarche. Mother was the most common source $(52.5 \%)$ of knowledge of menstruation before their menarche. Only $38.7 \%$ girls knew that bleeding occurs from uterus. Out of total, $71.3 \%$ girls knew that the menstruation is a physiological process. Table 4 shows $80.7 \%$ girls used sanitary napkins during menstruation. Ninety two percent girls faced restrictions regarding religious matters during menstruation. Table 5 shows that $84 \%$ girls took bath daily during menstruation and $90 \%$ washed their hands every time after visit to the toilet. In this study, $75.3 \%$ girls washed their external genitalia regularly.

\begin{tabular}{|c|c|c|}
\hline Age in Years & No. & \% \\
\hline $11-12$ & 30 & 20 \\
$13-14$ & 56 & 37.3 \\
14-16 & 64 & 42.7 \\
\hline \multicolumn{2}{|r|}{ Table 1: Age wise distribution of study subjects $\boldsymbol{n}=150$} \\
\hline
\end{tabular}

\begin{tabular}{|c|c|c|}
\hline Age of Menarche (Years) & No. & \% \\
\hline 11 & 21 & 14 \\
12 & 65 & 43.3 \\
13 & 35 & 23.3 \\
14 & 24 & 16 \\
15 & 5 & 3.3 \\
\hline \multicolumn{2}{|c|}{ their age of Menarche (n=150) } \\
\hline
\end{tabular}

*The mean age of menarche of the adolescent girls was $12.76 \pm 0.936$ years.

\begin{tabular}{|c|c|c|}
\hline Attributes & Number & Percentage \\
\hline $\begin{array}{l}\text { Awareness about } \\
\text { menstruation before } \\
\text { menarche } \\
\end{array}$ & 143 & 95.3 \\
\hline \multicolumn{3}{|c|}{$\begin{array}{l}\text { Source of knowledge of menstrual cycle before } \\
\text { menarche }\end{array}$} \\
\hline Mother & 75 & 52.5 \\
\hline Sister & 33 & 23.1 \\
\hline Friend & 35 & 24.5 \\
\hline \multicolumn{3}{|c|}{ Knowledge of organ from where bleeding occurs } \\
\hline Uterus & 58 & 38.7 \\
\hline Bladder & 76 & 50.7 \\
\hline Do not know & 16 & 10.7 \\
\hline \multicolumn{3}{|c|}{ Knowledge of cause of menstruation } \\
\hline Physiological & 107 & 71.3 \\
\hline God given & 18 & 12 \\
\hline Do not know & 25 & 16.7 \\
\hline \multicolumn{3}{|c|}{$\begin{array}{l}\text { What absorbent ideally to be used during } \\
\text { menstruation }\end{array}$} \\
\hline Sanitary pads & 132 & 88 \\
\hline Cloths & 18 & 12 \\
\hline \multicolumn{3}{|c|}{$\begin{array}{c}\text { Table 3: Distribution of school adolescent girls } \\
\text { according to their knowledge about menstruation } \\
(n=150)\end{array}$} \\
\hline
\end{tabular}




\begin{tabular}{|c|c|c|}
\hline Attributes & Number & Percentages \\
\hline \multicolumn{3}{|c|}{ Type of Absorbent $(n=150)$} \\
\hline Sanitary pads & 121 & 80.7 \\
\hline New cloths & 07 & 4.7 \\
\hline Old washed cloths & 22 & 14.7 \\
\hline \multicolumn{3}{|c|}{$\begin{array}{l}\text { Problems faced while using old washed cloth during } \\
\text { washing and drying }(n=22)\end{array}$} \\
\hline Yes & 16 & 72.7 \\
\hline No & 6 & 27.3 \\
\hline \multicolumn{3}{|c|}{$\begin{array}{l}\text { Different restrictions imposed to adolescent girls } \\
\text { during menstruation }(\mathrm{n}=150)^{*}\end{array}$} \\
\hline Religious matters & & \\
\hline Cooking and handling food & 138 & 92 \\
\hline items & 68 & 45.3 \\
\hline $\begin{array}{l}\text { Outdoor activities } \\
\text { including games }\end{array}$ & 34 & 22.7 \\
\hline \multicolumn{3}{|c|}{$\begin{array}{c}\text { Table 4: Distribution of school adolescent girls } \\
\text { according to their practices, problems and restrictions } \\
\text { during menstruation }\end{array}$} \\
\hline
\end{tabular}

* Multiple responses

\begin{tabular}{|c|c|c|}
\hline Attributes & Number & Percentages \\
\hline \multicolumn{3}{|c|}{ Daily Bath } \\
\hline Yes & 126 & 84 \\
\hline No & 24 & 16 \\
\hline \multicolumn{3}{|c|}{ Hand Washing } \\
\hline $\begin{array}{l}\text { Regular* } \\
\text { Irregular }\end{array}$ & 135 & 90 \\
\hline \multicolumn{3}{|c|}{ Cleaning of External Genitalia } \\
\hline \multirow[t]{2}{*}{ Regular** Irregular } & 113 & 75.3 \\
\hline & 37 & 24.7 \\
\hline \multicolumn{3}{|c|}{$\begin{array}{c}\text { Table 5: Distribution of school adolescent girls } \\
\text { according to their hygiene related practices during } \\
\text { menstruation }(n=150)\end{array}$} \\
\hline
\end{tabular}

* Regular: Hand washing every time after visit to the toilet during menstruation;

** Regular: Frequency of cleaning of external genitalia is $\geq 2$ /day;

\section{DISCUSSION}

In this study, the mean age of menarche of the adolescent girls was $12.76 \pm 0.936$ years, whereas another studies conducted by Khanna et al. ${ }^{7}$ and by Kajal Jain et al. ${ }^{8}$ the mean age of menarche was 13.2 years 13.16 years, respectively. In this study $52.5 \%$ study subjects got information regarding menstruation before their menarche by their mother followed by their sister similar findings were found by Kajal Jain et al. ${ }^{8}$, whereas another study conducted by El-Gilany et al. ${ }^{9}$ mass media was the main source of information followed by mothers. Another study conducted by Deo et al. ${ }^{10}$ reported that $42.5 \%$ urban and $55.4 \%$ rural girls were aware about menstruation prior to attainment of menarche. In urban girls, mother was the main source of information about menstruation $(27.5 \%)$, whereas it was teacher in the rural counterparts $(27.01 \%)$.

However, in this study only $4.7 \%$ girls were ignorant about menstruation before menarche, but each and every girl child should be aware about menstruation and ideally a mother should be the main informant at this tender age. Present study also reported that $71.3 \%$ girls believed menstruation to be a physiological process, whereas in a similar study conducted in by Khanna et al. 7 , nearly $70 \%$ believed that menstruation was not a natural process. In this study $38.7 \%$ girls knew about the origin of menstrual bleeding. Whereas research done in Andhra Pradesh University by Drakshayani et al. ${ }^{11}$ reported that around $78.5 \%$ subjects knew menstrual bleeding originated from the uterus. In this study $88 \%$ girls knew that sanitary pads are better than cloths however only $80.7 \%$ girls used the sanitary pad during menstruation. A study by Dasgupta et al.12 in a rural community showed that majority of the girls preferred cloth pieces rather than sanitary pads as menstrual absorbent. Only $11.25 \%$ girls used sanitary pads during menstruation.

In a study conducted by Khanna et al. ${ }^{7}$, three-fourths of the girls used old cloth during their periods and only one-fifth reported using readymade sanitary pads. In this study $14.7 \%$ girls used old cloth, while only $4.7 \%$ used new cloth during menstruation. These are due to differences in their sociocultural profile. It was also observed that the usual practice was to wash the cloth with soap after use and keep it at some secret place till the next menstrual period. To maintain privacy, these are sometimes hidden in unhygienic places. In this study although only $14.7 \%$ used old washed cloth and out of them $72.7 \%$ faced problems of lack of privacy while washing and drying cloth pieces used as absorbents during menstruation.

Regarding hygiene related practices during menstruation, $84 \%$ girls took daily bath during menstruation and $90 \%$ washed their hands every times after visit to the toilet during menstruation. Also $75.3 \%$ of study subjects cleaned their genitalia regularly. Educating young girls about the routine practice of taking a bath with warm water in the early days of menstrual period, would not only lead to the development of positive mental and social behaviours, but could also be effective in reducing hygiene related problems in the community.

\section{LIMITATIONS}

Considering the limitations of this study in terms of sampling method, additional studies may be needed using a wider geographic scope and a larger sample size.

\section{CONCLUSION}

Although knowledge was better than practice, so the girls should be educated about the process and significance of menstruation, use of proper pads or absorbents and its proper disposal. This can be achieved by giving them proper training and health education by teachers, family members, health educators and media; so that there would not be any misconception to the adolescent girls regarding menstrual hygiene.

\section{ACKNOWLEDGMENTS}

We gratefully acknowledge the active participation of adolescent girls and the Principal and Teachers of Senior Secondary Girls School for their co-operation in supporting the study. We are also thankful to our Multipurpose Health Workers for their support and help rendered.

\section{BIBLIOGRAPHY}

1. Dhingra R, Kumar A. Knowledge and practices related to menstruation among tribal (Gujjar) adolescent girls. Etho-Med 2009;3(1):43-48. 
2. Mudey AB, Keshwani N, Mudey GA, et al. A crosssectional study on the awareness regarding safe and hygienic practices amongst school going adolescent girls in the rural areas of Wardha district. Global Journal of Health Science 2010;2(2):225-231.

3. Dr Shamima Yasmin, Dr Nirmalya Manna, Dr Sarmila Mallik, et al. Menstrual hygiene among adolescent school students: An in-depth cross-sectional study in an urban community of West Bengal, India. IOSR Journal of Dental and Medical Sciences 2013;5(6):22-26.

4. Adolescents in India. A Profile. World Health Organization. 2003. Available at:http://www.whoindia.org/LinkFiles/Adolescent_Hea lth_and_Development_(AHD)_UNFPA_Country_Report.p df (Accessed on August 12, 2011).

5. Rao S, Joshi S, Kanade A. Height velocity, body fat and menarcheal age of Indian girls. Indian Pediatr 1998;35:619-28.

6. Singh MM, Devi R, Garg $S$, et al. Effectiveness of syndromic approach in management of reproductive tract infections in women. Indian J Med Sci 2001;55(4):209-14.
7. Khanna A, Goyal RS, Bhawsar R. Menstrual practices and reproductive problems: a study of adolescent girls in Rajasthan. J Health Manag 2005;7:91-107.

8. Kajal Jain, Garg SK, Singh JV, et al. (2009). Reproductive health of adolescent girls in an urban population of Meerut, Uttar Pradesh Health and Population: Perspectives and Issues. 32(4):204-209.

9. El-Gilany AH, Badawi K. Menstrual hygiene among adolescent schoolgirls in Mansoura, Egypt. Reprod Health Matters 2005;13:147-52.

10. Deo DS, Ghattargi CH. Perceptions and practices regarding menstruation: a comparative study in urban and rural adolescent girls. Indian J Community Med 2005;30:33-4.

11. Drakshayani Devi K, Venkata Ramaiah P. A study on menstrual hygiene among rural adolescent girls. Indian J Med Sci 1994;48:139-43.

12. Dasgupta A, Sarkar M. Menstrual Hygiene: how hygienic is the adolescent girl? Indian Journal of Community Medicine 2008;33(2):78-80. 